\title{
BMJ A systematic review of the effect of red blood cell transfusion on mortality: evidence from large-scale observational studies published between 2006 and 2010
}

\author{
Sally Hopewell, ${ }^{1,2}$ Omar Omar, ${ }^{2}$ Chris Hyde, ${ }^{3}$ Ly-Mee Yu, ${ }^{2}$ Carolyn Doree, ${ }^{1}$ \\ Mike F Murphy ${ }^{1}$
}

To cite: Hopewell S, Omar 0, Hyde $\mathrm{C}$, et al. A systematic review of the effect of red blood cell transfusion on mortality: evidence from largescale observational studies published between 2006 and 2010. BMJ Open 2013;3: e002154. doi:10.1136/ bmjopen-2012-002154

- Prepublication history and additional material for this paper are available online. To view these files please visit the journal online (http://dx.doi.org/10.1136/ bmjopen-2012-002154).

Received 24 September 2012 Revised 11 March 2013 Accepted 25 March 2013

This final article is available for use under the terms of the Creative Commons Attribution Non-Commercial 2.0 Licence; see http://bmjopen.bmj.com

${ }^{1}$ Systematic Review Initiative, NHS Blood and Transplant, Department of Haematology, Oxford University Hospitals and University of Oxford, Oxford, UK

${ }^{2}$ Centre for Statistics in Medicine, University of Oxford, Oxford, UK ${ }^{3}$ PenTAG, Peninsula College of Medicine and Dentistry, Exeter, UK

\section{Correspondence to} Dr Sally Hopewell;

sally.hopewell@csm.ox.ac.uk

\section{ABSTRACT}

Objective: To carry out a systematic review of recently published large-scale observational studies assessing the effects of red blood cell transfusion (RBCT) on mortality, with particular emphasis on the statistical methods used to adjust for confounding. Given the limited number of randomised trials of the efficacy of RBCT, clinicians often use evidence from observational studies. However, confounding factors, for example, individuals receiving blood generally being sicker than those who do not, make their interpretation challenging.

Design: Systematic review.

Information sources: We searched MEDLINE and EMBASE for studies published from 1 January 2006 to 31 December 2010.

Eligibility criteria for included studies: We included prospective cohort, case-control studies or retrospective analyses of databases or disease registers where the effect of risk factors for mortality or survival was examined. Studies must have included more than 1000 participants receiving RBCT for any cause. We assessed the effects of RBCT versus no RBCT and different volumes and age of RBCT.

Results: -32 studies were included in the review; 23 assessed the effects of RBCT versus no RBCT; 5 assessed different volumes and 4 older versus newer RBCT. There was a considerable variability in the patient populations, study designs and level of statistical adjustment. Overall, most studies showed a higher rate of mortality when comparing patients who received RBCT with those who did not, even when these rates were adjusted for confounding; the majority of these increases were statistically significant. The same pattern was observed in studies where protection from bias was likely to be greater, such as prospective studies.

Conclusions: Recent observational studies do show a consistently adverse effect of RBCT on mortality.

Whether this is a true effect remains uncertain as it is possible that even the best conducted adjustments cannot completely eliminate the impact of confounding.

\section{ARTICLE SUMMARY}

\section{Article focus}

- Given the limited number of randomised trials of the efficacy of red blood cell transfusion (RBCT), clinicians often use evidence from observational studies.

- Confounding factors, for example individuals receiving blood generally being sicker than those who do not, can make their interpretation challenging.

- Our objective was to systematically review large observational studies ( $\mathrm{n}>1000$ patients) published in the last 5 years assessing the effect of RBCT on mortality, with particular emphasis on the statistical methods used to adjust for confounding.

Key messages

- We identified considerable variability in the patient populations, study designs and levels of statistical adjustment.

- Most studies showed higher death rates when comparing patients who received RBCT with those who did not, even when adjusting for confounding. We identified similar patterns in studies where protection from bias was likely to be greatest.

Strengths and limitations of this study

- Overall, observational studies do show a consistently adverse effect of RBCT on mortality.

- However, even the best conducted adjustments for confounding cannot completely eliminate its impact, particularly when investigating the effect of RBCT on mortality.

\section{INTRODUCTION}

Randomised controlled trials are considered the gold standard with which to evaluate the efficacy of a particular healthcare intervention. In 2005, Blajchman ${ }^{1}$ published a study that explored the impact that 10 landmark randomised controlled trials have had on the practice of transfusion medicine. The use of 
randomised trials to evaluate transfusion medicine has only been established since the $1980 \mathrm{~s}^{1}{ }^{1}$ Given the limited number of high-quality randomised trials of the efficacy of blood transfusion and the challenges of conducting new trials, clinicians often rely on evidence from observational studies. In a randomised trial, patients are allocated to compare groups at random, so the level of disease is likely to be similar in each group and differences in disease severity unlikely to be the explanation for any differences in outcome seen. In an observational study, the groups of patients being compared are not likely to be comparable and the differences in prognostic factors may of themselves lead to differences in outcome. The impact of such 'confounding' can be reduced by adjustment in the statistical analysis, but the success of this is dependent on the technique used, complete identification of the factors which might influence outcome and their accurate measurement in the patients in the study. ${ }^{2}$ As all the factors influencing outcome may never be known, adjustment is unlikely to ever completely account for the confounding occurring in observational studies. The unknown interdependence of multiple factors is also a major challenge.

There is increasing implementation of restrictive policies for transfusion, and evidence of reduction in blood use in several countries such as the UK and the USA with no evidence of poorer clinical outcomes. ${ }^{3} 4$ However, there remains considerable variation between hospitals in blood reduction in the $\mathrm{UK}^{5}$ and elsewhere, ${ }^{6}$ suggesting that overall blood usage could be further reduced without compromising patient safety. Observational studies may have influenced these changes in transfusion practice along with evidence from randomised controlled trials, national guidelines and process-driven initiatives, but the impact that the contribution of data from observational studies has made to the practice of transfusion medicine has not been systematically explored. The aims of this systematic review were therefore to identify recently published (2006-2010), large-scale observational studies assessing the effects of red blood cell transfusion (RBCT) on mortality. In particular, we aimed to critique the statistical methods and the assumptions made in the analyses of the observational data, and to consider the validity of these data as an evidence base for the practice of transfusion medicine and to inform future research in this field.

\section{METHODS}

\section{Criteria for selecting studies}

Type of participants

We included both adults and children receiving RBCT for any cause. We also included studies which stated that patients received red blood cells and other blood products. When reported by the primary studies, we assessed the effects of RBCT separately from other blood products.
Type of intervention and comparator

We included the following risk factors:

- RBCT versus no RBCT;

- Volume 'A' of RBCT versus volume 'B' of RBCT (as defined by the primary studies);

- 'Older' RBCT versus 'newer' RBCT (as defined by the primary studies).

\section{Type of outcome measure}

Our primary outcome measure was death, mortality or survival measured at any time point.

\section{Type of studies}

We included prospective cohort, case-control studies or retrospective analyses of databases or disease registers where the effect of the above risk factors on death, mortality or survival is examined. Studies must have included more than 1000 participants. This was a pragmatic limit designed to focus attention on studies most likely to have had an impact and least likely to have been affected by chance.

\section{Search strategy}

We carried out a comprehensive search (21 January 2011) of MEDLINE and EMBASE for studies published from 1 January 2006 to 31 December 2010 using the strategies in online supplementary appendix 1. Again, we chose to use a pragmatic approach and limited our search to studies published in the last 5 years. We also excluded conference abstracts unless they had subsequently been published as full articles.

\section{Data collection and analysis}

One review author (CD) initially screened all search results for relevance against the eligibility criteria and discarded all those that were clearly irrelevant. Thereafter, another author $(\mathrm{SH})$ independently screened all remaining hits. We retrieved full text articles for all those references where we are unable to decide on eligibility based on the title and abstract alone. All full text articles were independently screened by two review authors (SH and MFM) to ensure that they met the eligibility criteria.

\section{Data extraction and management}

Two review authors ( $\mathrm{SH}$ and $\mathrm{OO}$ ) independently extracted data from all included studies. Any disagreements were resolved by discussion or by consulting a third author if there was still uncertainty. We extracted data on the following study characteristics: the study design, how patients were recruited, the country where the study was conducted, the source of funding, the type of participants, their age, disease area, setting, the type of intervention/comparator and nature of the exposure, the number of participants in each group, whether any formal prescribing guidance was reported, the type of outcome measure (ie, mortality) and the time point at which it was measured.

We also extracted information on the statistical methods used to adjust for differences between study 
groups, in particular the number of study covariates measured, whether important covariates relating to red cell transfusion were assessed (ie, age, sex, comorbidity and haemoglobin) and whether these were incorporated in the analysis, whether the choice of covariates were prespecified or data driven and the statistical model used for the statistical adjustment. We also assessed the effects of smoking as a study covariate in relation to blood transfusion and its effect on mortality. In terms of the study results, we extracted data on the presentation of both the unadjusted and adjusted results for the effect of red cell transfusion on mortality as reported by each study. If not reported by the primary study, we calculated (where there were sufficient data) the OR for the effects of blood transfusion on mortality for unadjusted analyses using STATA (V.11). We assessed, for the unadjusted and adjusted results, whether the study reported summary statistics for each comparison group, the treatment effect, CI, p value and whether the result was statistically significant. If a study reported more than one adjusted analysis, we selected in order of preference (1) the main adjusted analysis mentioned in the abstract, (2) the main adjusted analysis mentioned in the conclusions and (3) the main adjusted analysis mentioned in the results section. If mortality was assessed for more than one time point (ie, at 30 days and 1 year), then we used the shorter time point in our analysis.

\section{Assessment of methodological quality}

We also assessed whether studies met important methodological criteria for the reporting of observational studies': whether the samples were representative of those to whom the results might be generalised, whether important covariates in relation to RBCT and mortality (eg, sex, age, smoking, comorbidity, haemoglobin level) were measured and incorporated in the analysis, whether the method of dealing with confounding between patient groups was adequate, whether a statistician was listed as an author of the study and whether the data were collected prospectively following an agreed study design. We included smoking as a covariate as, while not directly correlated with transfusion, it is considered to be important when assessing mortality.

\section{Method of analysis}

We have presented the results separately for the three different types of comparisons. Within each, owing to the varied nature of the clinical conditions, study designs and level of statistical adjustment, we decided a priori not to combine the results of individual studies in a meta-analysis and instead present the results of the individual studies descriptively in the text, tables and figures.

\section{RESULTS}

Searches of MEDLINE and EMBASE identified 4318 possible records. In total, 4272 did not meet the eligibility criteria for this study. Full articles were retrieved for 45 studies; 13 further studies were excluded as they did not fulfil our eligibility criteria (see online supplementary appendix 2 for list of excluded studies). Thirty-two studies were included in the review; $23^{7-30}$ studies assessed the effects of RBCT versus no RBCT, 5 studies ${ }^{31-35}$ assessed different volumes of RBCT and $4^{36-39}$ assessed giving older versus newer RBCT (see figure 1).

\section{RBCT versus no RBCT}

Twenty-three studies $^{7-30}$ assessed the effects of RBCT versus no RBCT on mortality. Four of these studies $^{8} 121421$ included both red cell transfusion and other blood products (eg, platelets, plasma and cryoprecipitate); for one study, data were available separately for RBCT and mortality. ${ }^{14}$ For three studies, it was unclear if other blood products were transfused along with red blood cells. ${ }^{11} 1322$

\section{Study characteristics}

Eight studies were prospective cohort studies following up a planned group of patients, ${ }^{7} 8151618$ 24-27 whereas the other 15 studies assessed data from a retrospective patient registry or database (table 1 ). Fourteen studies were conducted in the USA, two in the UK, two in Israel and the remainder in Belgium, the Netherlands, Iran and Denmark; one study was conducted in multiple countries. The time period assessed was between 1989 and 2008. Twelve of the studies ${ }^{7} 911$ 12 15-18 20-22 2426 specifically looked at adults undergoing cardiac surgery, five were on patients in the intensive care unit, ${ }^{1025272930}$ two were on adults trauma patients, ${ }^{8} 28$ two were on patients following hip fracture/replacement $^{1319}$ one was on oncology patients ${ }^{14}$ and the other on paediatric trauma patients. ${ }^{23}$ Three of the studies $^{12} 2021$ specifically looked at the effects of RBCT in older adults (eg, $>60$ years). The size of the studies varied from 1624 participants to 504208 participants with an overall median sample size of 4344 (IQR 208511963); median 1068 (IQR 430-5812) for patients undergoing RBCT compared with median 2325 (IQR 1636-6151) for patients with no RBCT. The time period at which mortality was assessed also varied across studies from in-hospital to mortality at 7 years; the most common time point being mortality at or within 30 days. Several studies reported mortality for more than one time period. Only 7 of the 23 studies provided any mention of guidelines for the prescription of RBCT; 2 studies said that no formal protocol was used, ${ }^{8} 232$ studies stated a haemoglobin $<8 \mathrm{~g} / \mathrm{dl}^{1},{ }^{10}{ }^{13} 1$ study stated a haematocrit of less than $25-26 \%^{22}$ and 2 studies said that prescription was at the discretion of the patient care team. $^{24}{ }^{25}$ For full details of the characteristics of the included studies, see online supplementary appendix 3 .

\section{Statistical methods}

All 23 studies provided information on the statistical methods used to adjust for differences in the baseline characteristics of patients who received RBCT and those 
Figure 1 Flow diagram of study inclusion (1 January 2006 to 31 December 2010).

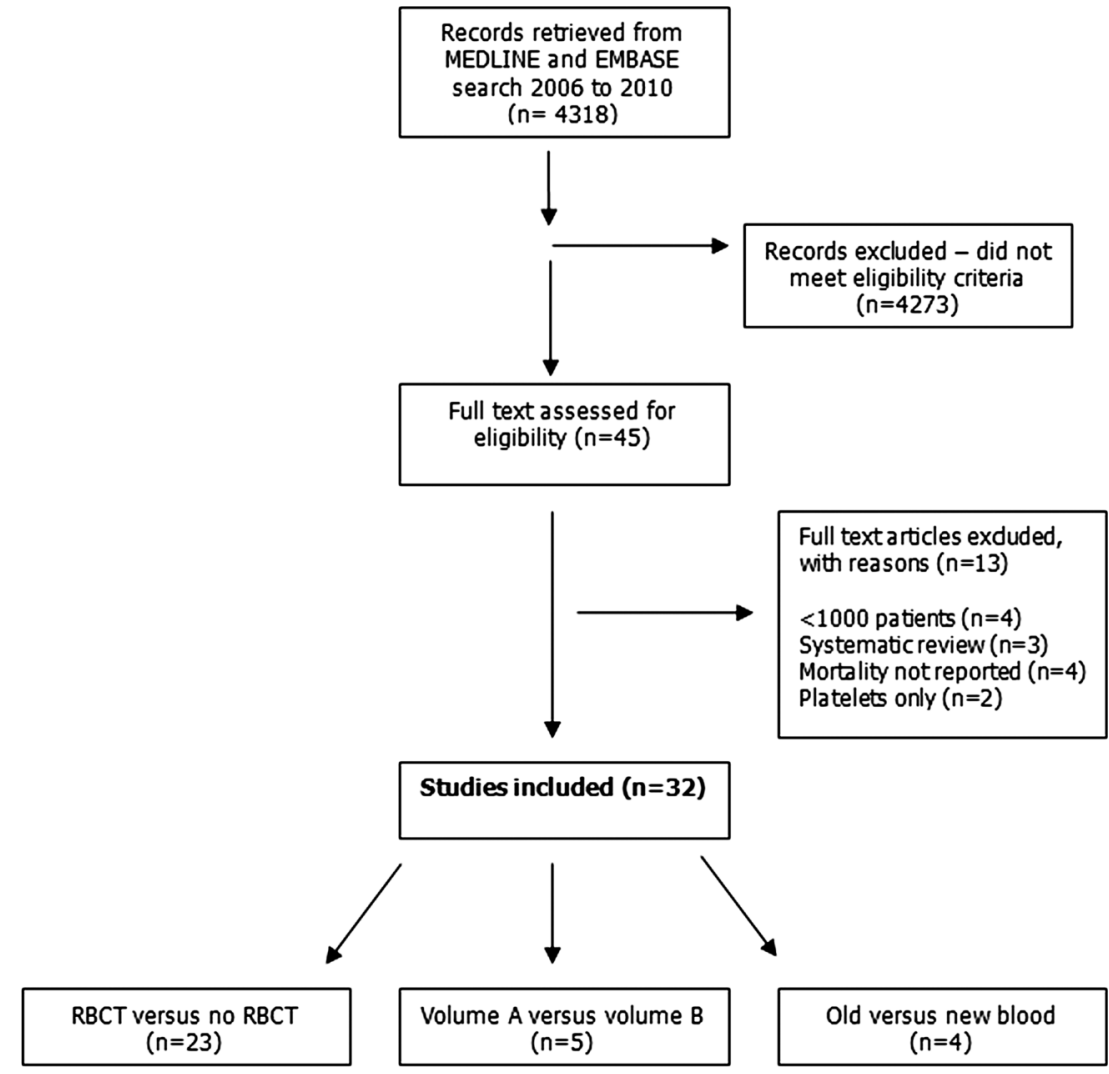

who did not (table 2). However, the amount of detail and appropriateness of the method used varied across studies. In 13 studies, $791014-192224252730$ the choices of covariates measured were reported as prespecified and not data driven, but this was unclear for the remaining 10 studies. The number of covariates measured and incorporated in the analysis also varied across studies with half the studies reported to assess more than 20 different covariates. Despite the high number of covariates assessed in these studies, not all measured covariates which appeared to be of specific importance in relation to RBCT. All of the 23 studies did report measuring the age and sex of the patients and 21 reported measuring patient comorbidity. Overall, only eight $\begin{array}{llllll}11 & 12 & 15-18 & 22 & 29\end{array}$ studies measured and incorporated the covariates age, sex, smoking, comorbidity and haemoglobin level in the adjusted analysis. Fourteen of the 23 studies reported using logistic regression (ie, mortality was reported as a binary outcome) as the method of adjusting for differences in the baseline characteristics between the two patient groups; six studies reported using the Cox proportional hazard (ie, mortality was reported as a time to event outcome) and three studies reporting using both methods; in these three studies, mortality was assessed for more than one time period. Nine studies $7 \begin{array}{llll}12 & 17-19212729 & & \\ & & & \end{array}$ scores prior to adjusting for confounders; however, sometimes this matching was done only by using a much smaller subgroup of patients. For full details of the statistical methods, see online supplementary appendix 4 .

\section{Presentation of adjusted and unadjusted results}

There were marked differences in the presentation and reporting of the unadjusted and adjusted results when comparing the effects of RBCT versus no RBCT on mortality (table 3). Seven of the 23 studies reported summary statistics for each group for both the unadjusted and adjusted analyses. Five studies reported summary statistics for only the unadjusted analysis and one study for the adjusted analysis only; no summary statistic comparing the effects of RBCT versus no RBCT on mortality was reported in the remaining 10 studies. Eight studies reported the treatment effect (eg, OR, risk ratio and $\mathrm{HR}$ ) and the corresponding confident interval (six studies) for both the unadjusted and adjusted analysis, ${ }^{7} 151618-20242630$ whereas 12 studies reported the treatment effect and confident interval (10 studies) for adjusted analysis only and one study for the unadjusted analysis only. Where possible, we calculated the OR for the effect of RBCT on mortality for unadjusted analyses if it was not reported in the published article.

Seventeen of the 23 studies reported a statistically significant result for the unadjusted analysis, and 15 for the adjusted analysis (figure 2), when comparing the effect of RBCT versus no RBCT on mortality, with more deaths occurring in patients receiving transfusion. This effect was statistically non-significant in seven studies based on the 
Table 1 Summary of characteristics of included studies

\begin{tabular}{|c|c|c|c|}
\hline Type of comparison & RBCT vs no RBCT ( $n=23)$ & Volume 'A' vs Volume 'B'( $n=5)$ & Old RBC vs new RBC $(n=4)$ \\
\hline \multicolumn{4}{|l|}{ Design } \\
\hline Prospective & $8(35 \%)$ & $1(20 \%)$ & \\
\hline Retrospective & $15(65 \%)$ & $4(80 \%)$ & $4(100 \%)$ \\
\hline \multicolumn{4}{|l|}{ Country } \\
\hline Australia & & $1(20 \%)$ & \\
\hline Belgium & $1(4 \%)$ & & \\
\hline Denmark & $1(4 \%)$ & & \\
\hline Germany & & $1(20 \%)$ & \\
\hline Iran & $1(4 \%)$ & & \\
\hline Israel & $2(9 \%)$ & & \\
\hline The Netherlands & $1(4 \%)$ & & $1(25 \%)$ \\
\hline Sweden & & & $1(25 \%)$ \\
\hline The USA & $14(61 \%)$ & $3(60 \%)$ & $2(50 \%)$ \\
\hline The UK & $2(9 \%)$ & & \\
\hline (multiple sites) & $1(4 \%)$ & & \\
\hline Time period assessed & $1989-2008$ & 1993-2007 & 1993-2007 \\
\hline \multicolumn{4}{|l|}{ Sample size (median, IQR) } \\
\hline All patients & 4344 (IQR 2085-11963) & 8215 (IQR 3037-8799) & 4358 (2264-185019) \\
\hline RBC transfusion & 1068 (IQR 430-5812) & & \\
\hline No RBC transfusion & 2325 (IQR 1636-6151) & & \\
\hline \multicolumn{4}{|l|}{ Disease area } \\
\hline Cardiac surgery & $12(52 \%)$ & $2(40 \%)$ & $2(50 \%)$ \\
\hline Hip fracture/replacement & $2(9 \%)$ & & \\
\hline Intensive care & $5(22 \%)$ & $1(20 \%)$ & \\
\hline Oncology & $1(4 \%)$ & & \\
\hline Surgery & & $1(20 \%)$ & \\
\hline Trauma adults & $2(9 \%)$ & $1(20 \%)$ & $1(25 \%)$ \\
\hline Trauma paediatrics & $1(4 \%)$ & & \\
\hline Not reported & & & $1(25 \%)$ \\
\hline \multicolumn{4}{|l|}{ Prescribing guidance } \\
\hline Reported & $7(30 \%)$ & $3(60 \%)$ & \\
\hline Not reported & $16(70 \%)$ & $2(40 \%)$ & $4(100 \%)$ \\
\hline \multicolumn{4}{|l|}{ Mortality assessed ${ }^{*}$} \\
\hline In hospital & 8 & 2 & 2 \\
\hline 30 days & 10 & 2 & 1 \\
\hline 3 months & 3 & & \\
\hline 6 months & 3 & & \\
\hline$>1$ year & 4 & 1 & 2 \\
\hline Time period not specified & 2 & & 1 \\
\hline
\end{tabular}

result of the adjusted analysis. Prospective studies were more likely to show a statistically significant effect for blood transfusion on mortality compared with retrospective studies for both the unadjusted and adjusted analyses. For full details, see online supplementary appendix 5 .

Volume 'A' red blood versus volume 'B' red blood cells Five studies ${ }^{31-35}$ assessed the effects of different volumes of RBCT on mortality. One of these studies ${ }^{35}$ included both RBCT and other blood products.

\section{Study characteristics}

One study assessed a prospective cohort and followed up a planned group of patients, ${ }^{35}$ whereas the other four studies assessed data from a retrospective patient registry or database. Two of the studies ${ }^{33} 35$ specifically looked at adults undergoing cardiac surgery, one was on trauma patients, ${ }^{32}$ one was on patients undergoing major surgery $^{31}$ and one on patients in the intensive care unit. ${ }^{34}$ The size of the studies varied from 1841 participants to 125177 participants, with an overall median sample size of 8215 (IQR 3037-8799). The volume of RBCT varied considerably across studies from 1 to 2 units to more than eight units. The time period at which mortality was assessed also varied across studies from in-hospital to mortality at 8 years. Three of the five studies provided any mention of guidelines for the prescription of red blood cells; however, only one gave any specific requirement stating a haemoglobin of $<8 \mathrm{~g} / \mathrm{dl}^{34}$ (see table 1; online supplementary appendix 3 ). 
Table 2 Method of adjusted analysis

\begin{tabular}{|c|c|c|c|}
\hline Type of comparison & $\begin{array}{l}\text { RBCT vs no RBCT } \\
(\mathrm{n}=23)\end{array}$ & $\begin{array}{l}\text { Volume 'A' vs Volume 'B' } \\
(n=5)\end{array}$ & $\begin{array}{l}\text { Old RBC vs new RBC } \\
(n=4)\end{array}$ \\
\hline \multicolumn{4}{|l|}{ Choice of covariates } \\
\hline Prespecified & $13(57 \%)$ & $5(100 \%)$ & $4(100 \%)$ \\
\hline \multicolumn{4}{|l|}{ Post hoc } \\
\hline Unclear & $10(43 \%)$ & & \\
\hline \multicolumn{4}{|l|}{ No. of covariates measured } \\
\hline $1-5$ & $2(9 \%)$ & & \\
\hline $6-10$ & $4(17 \%)$ & $1(20 \%)$ & $2(50 \%)$ \\
\hline $11-20$ & $3(13 \%)$ & $2(40 \%)$ & \\
\hline$>20$ & $12(52 \%)$ & $2(40 \%)$ & $1(25 \%)$ \\
\hline Unclear & $2(9 \%)$ & & $1(25 \%)$ \\
\hline \multicolumn{4}{|c|}{ Important covariates assessed } \\
\hline Age & $23(100 \%)$ & $5(100 \%)$ & $4(100 \%)$ \\
\hline Sex & $23(100 \%)$ & $5(100 \%)$ & $4(100 \%)$ \\
\hline Smoking & $8(35 \%)$ & $1(20 \%)$ & $1(25 \%)$ \\
\hline Comorbidity & $21(91 \%)$ & $5(100 \%)$ & $3(75 \%)$ \\
\hline $\mathrm{Hb}$ level & $14(61 \%)$ & $4(80 \%)$ & $2(50 \%)$ \\
\hline \multicolumn{4}{|c|}{$\begin{array}{l}\text { Important covariates incorporated into } \\
\text { analysis }\end{array}$} \\
\hline Yes & $8(35 \%)$ & $1(20 \%)$ & $1(25 \%)$ \\
\hline No & $15(65 \%)$ & $4(80 \%)$ & $3(75 \%)$ \\
\hline \multicolumn{4}{|l|}{ Method of adjustment } \\
\hline Cox proportional hazard & $6(26 \%)$ & $1(20 \%)$ & $1(25 \%)$ \\
\hline Logistic regression & $14(61 \%)$ & $4(80 \%)$ & $2(50 \%)$ \\
\hline Both* & $3(13 \%)$ & & \\
\hline Not reported & & & $1(25 \%)$ \\
\hline
\end{tabular}

\section{Statistical methods}

All five studies provided information on the statistical methods used to adjust for differences in the baseline characteristics of patients who received different volumes of red blood transfusion, however, as with the studies of RBCT versus no RBCT, the amount of detail and appropriateness of the method used varied across studies. In all five studies, ${ }^{31-35}$ the choices of covariates measured were reported as prespecified. The number of covariates measured and incorporated in the analysis varied across studies with two of the studies reported to assess more than 20 different covariates. Once again, despite the high number of covariates assessed in these studies, not all measured covariates seem to be of specific importance in relation to RBCT. All five studies reported measuring age and sex and patient comorbidity; however, one ${ }^{31}$ measured and incorporated the covariates age, sex, smoking, comorbidity and haemoglobin level in the adjusted analysis (table 2).

\section{Presentation of adjusted and unadjusted results}

As with the studies of RBCT versus no RBCT, there were marked differences in the presentation and reporting of the unadjusted and adjusted results when comparing the effects of different volumes of RBCT on mortality. Two studies reported a statistically significant result for the adjusted analysis with more deaths occurring in patients receiving larger volumes of RBCT. This effect was statistically non-significant in two studies based on the result for adjusted analysis and was not reported for the remaining one study (table 3). No studies reported on the statistical significance of the result of the unadjusted analysis (see online supplementary appendices 4 and 5).

'Older' red blood cells versus 'newer' red blood cells Four $^{36-39}$ studies assessed the effects of age of RBCT on mortality, one of which specifically looked at leukodepleted RBCT. ${ }^{39}$

\section{Study characteristics}

All four studies assessed data from a retrospective patient registry or database. Two of the studies ${ }^{37} 38$ specifically looked at adults undergoing cardiac surgery, one was on trauma patients, ${ }^{39}$ while the other did not mention a specific patient group. The size of the studies varied from 1813 participants to 364037 participants, with an overall median sample size of 4358 (IQR 2264-185 019). The period of time in which the blood was stored varied considerably across studies. Two studies $^{37} 39$ assessed RBCT stored for less than 14 days compared with those stored for more than 14 days, one study $^{38}$ compared blood stored for less than 18 days and with blood stored for more than 18 days and one study ${ }^{36}$ 
Table 3 Presentation of results for unadjusted and adjusted analyses (mortality)

\begin{tabular}{|c|c|c|c|}
\hline Type of comparison & $\begin{array}{l}\text { RBCT vs no RBCT } \\
(n=23)\end{array}$ & $\begin{array}{l}\text { Volume 'A' vs Volume 'B' } \\
(n=5)\end{array}$ & $\begin{array}{l}\text { Old RBC vs new RBC } \\
(n=4)\end{array}$ \\
\hline \multicolumn{4}{|l|}{$\begin{array}{l}\text { Summary statistic for each } \\
\text { group }\end{array}$} \\
\hline Unadjusted only & $5(22 \%)$ & $2(40 \%)$ & \\
\hline Adjusted only & $1(4 \%)$ & & \\
\hline Both & $7(30 \%)$ & & $1(25 \%)$ \\
\hline Not reported & $10(44 \%)$ & $3(60 \%)$ & $3(75 \%)$ \\
\hline \multicolumn{4}{|l|}{ Treatment effect } \\
\hline Unadjusted only & $1(4 \%)$ & & \\
\hline Adjusted only & $12(52 \%)$ & $5(100 \%)$ & $2(50 \% \%)$ \\
\hline Both & $8(35)$ & & $1(25 \%)$ \\
\hline Not reported & $2(9 \%)$ & & $1(25)$ \\
\hline \multicolumn{4}{|l|}{$\mathrm{Cl}$ of treatment effect } \\
\hline \multicolumn{4}{|l|}{ Unadjusted only } \\
\hline Adjusted only & $10(43 \%)$ & $3(60 \%)$ & $2(50 \%)$ \\
\hline Both & $8(35 \%)$ & & $1(25 \%)$ \\
\hline Not reported & $5(22 \%)$ & $2(40 \%)$ & $1(25 \%)$ \\
\hline \multicolumn{4}{|l|}{$p$ Value for treatment effect } \\
\hline Unadjusted only & $7(30 \%)$ & & \\
\hline Adjusted only & & $1(20 \%)$ & \\
\hline Both & $1(4 \%)$ & & $1(25 \%)$ \\
\hline Not reported & $15(66 \%)$ & $4(80 \%)$ & $3(75 \%)$ \\
\hline \multicolumn{4}{|l|}{ Unadjusted analysis* } \\
\hline Statistically significant & $17(74 \%)$ & & $2(50 \%)$ \\
\hline Statistically non-significant & $1(4 \%)$ & & \\
\hline Not reported & $5(22 \%)$ & $5(100 \%)$ & $2(50 \%)$ \\
\hline \multicolumn{4}{|l|}{ Adjusted analysis* } \\
\hline Statistically significant & $15(65 \%)$ & $2(40 \%)$ & $1(25 \%)$ \\
\hline Statistically non-significant & $7(31 \%)$ & $2(40 \%)$ & $3(75 \%)$ \\
\hline Not reported & $1(4 \%)$ & $1(20 \%)$ & \\
\hline
\end{tabular}

looked at multiple storage periods ranging from 1 to 42 days (table 1). None of the studies provided any mention of guidelines for the prescription of red blood cells (see online supplementary appendix 2 ).

\section{Statistical methods}

All four studies provided information on the statistical methods used to adjust for differences in the baseline characteristics of patients who received RBCT stored for

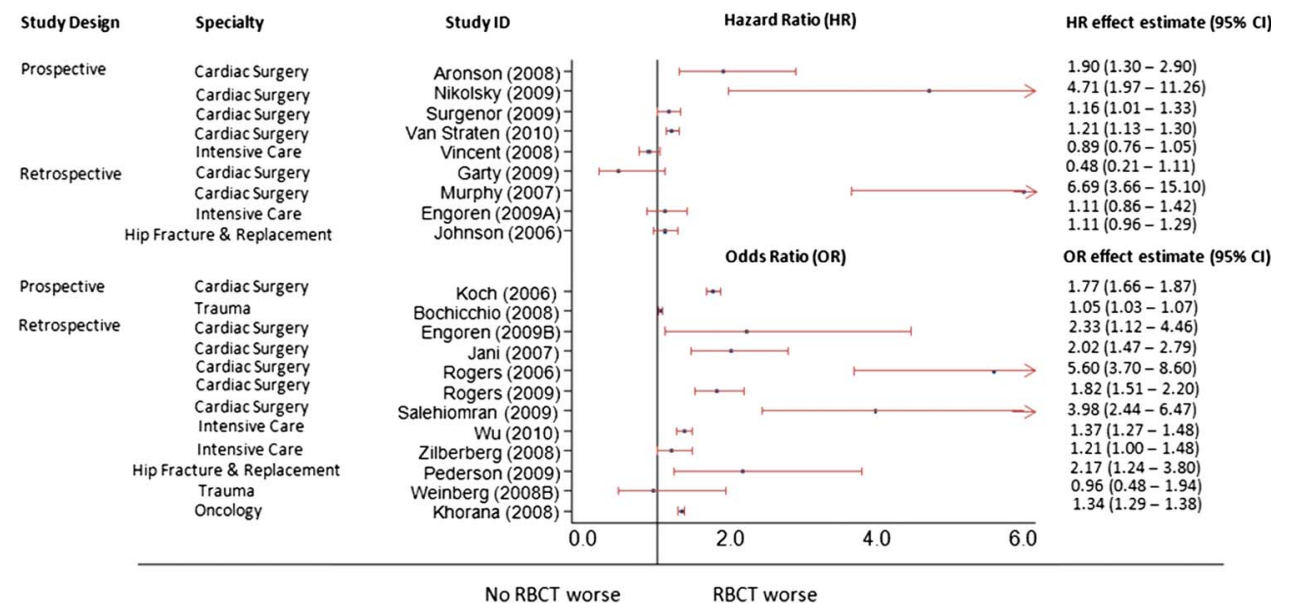

Figure 2 Effect of red blood cell transfusion versus no red blood cell transfusion on mortality (adjusted results). 
different time periods; however, once again, the amount of detail and appropriateness of the method used varied across studies. The number of covariates measured and incorporated in the analysis also varied across studies. All of the four studies reported measuring the age and sex of the participants. Only two studies reported measuring patient haemoglobin levels and three studies reported assessing patient comorbidities. Only one ${ }^{37}$ of the four studies measured and incorporated the covariates age, sex, smoking, comorbidity and haemoglobin level in the adjusted analysis (table 2).

\section{Presentation of adjusted and unadjusted results}

As with the studies of RBCT versus no RBCT and of volume 'A' red blood cells versus volume 'B' RBCT, there were marked differences in the presentation and reporting of the unadjusted and adjusted results when comparing the effects of RBCT stored for different time periods on mortality. Two studies reported a statistically significant result for the unadjusted analysis and one study reported a statistically significant result for the adjusted analysis. In two of these three studies, there were more deaths occurring in patients receiving older blood and in one study, there were more deaths in patients receiving newer blood. This effect was statistically non-significant in three studies based on the result for adjusted analysis (see table 3; online supplementary appendices 4 and 5).

\section{Assessment of methodological quality}

Overall, the assessment of methodological quality varied across studies and by study group with only 10 of the 32 included studies assessing a prospective cohort following up a planned group of patients over time; the remaining two-third of the studies assessed data from a retrospective patient registry or database. In most studies, the sample of patients included in the study was considered to be representative of those to whom the results might be generalised. Four studies ${ }^{12} 202129$ specifically focused on older adults ( $>60$ years) and one study ${ }^{23}$ on children, so the findings from these studies should only be interpreted in relation to these specific patient groups. The baseline characteristics of patients who received RBCT compared with those patients who did not receive RBCT (or patients who received different volumes or age of blood) were often very different, and so we wanted to assess whether the studies had adjusted for these differences when carrying out their statistical analysis. Only 10 studies measured and incorporated in the analysis covariates which we deemed to be of specific importance in relation to RBCT (ie, age, sex, smoking, comorbidity and haemoglobin level); thus, we deemed the method of dealing with confounding between patient groups as adequate in only $31 \%$ of studies. Critically however, when we restricted our analysis of results to studies with adequate methods, the pattern of an increase in mortality associated with RBCT remained unchanged (table 4).

\section{DISCUSSION}

\section{Summary of main findings}

We identified 32 observational studies of more than 1000 participants published between 2006 and 2010 assessing the effect of RBCT on mortality. Twenty-three studies compared RBCT versus no RBCT, five compared different volumes and four compared different storage times. Overal,1 there was considerable variability in the characteristics of the observational studies. However, the majority of studies were retrospective designs assessing patients from an existing patient register or database.

We also identified considerable variability in the statistical methods used to adjust for differences in the baseline characteristics of patients who received RBCT and those who did not. It was often unclear if the choices of the covariates measured and used in the adjusted analyses were prespecified at the start of the study or were driven by the underlying data. Perhaps most importantly, around half of the 32 studies did not measure and adjust for covariates which we deemed to be of specific importance to blood transfusion.

Overall, more studies found a higher rate of mortality in patients receiving RBCT compared with those who did not, and this effect was seen in both the adjusted and unadjusted results. In general, where measured equivalently within the same study, the unadjusted estimate of risk was greater than the adjusted risk, emphasising that adverse prognostic factors are more common in patients receiving RBCT and that adjusting for them leads to a smaller estimate of risk. Considering the adjusted risks, although the size of the effect was not consistent across all studies, the direction of the effect was. Most studies suggest an increased risk of mortality associated with RBCT. Further, those studies which were designed prospectively and which used better methods of adjusting for differences in the baseline characteristics between groups were more likely to show an increase in the risk of mortality compared with studies which were based on retrospective registries or databases, although, again, the size of the effect was not consistent across all studies. However, it is important to remember that even with the best methods of adjustment, it cannot completely eliminate the impact of confounding, ${ }^{2}$ as the sicker the patients (thus, an increased risk of mortality), the more likely they are to have received RBCT.

\section{Comparison with other studies}

We are aware of one other systematic review of observational studies looking at the effects of RBCT on mortality, which focused specifically on critically ill adults in intensive care units and adult trauma and surgical patients. ${ }^{40}$ This systematic review by Marik and colleagues included more studies $(n=45)$ than our review as it did not restrict its inclusion criteria to studies with $>1000$ patients; the median number of patients analysed was 687. They also found that RBCT was associated with an increased risk of mortality based on a meta-analysis of 12 studies (OR 1.7; 95\% CI 1.4 to 1.9). However, there was 
Table 4 Assessment of methodological quality of the included studies

\begin{tabular}{|c|c|c|c|c|c|}
\hline Study ID & $\begin{array}{l}\text { Data collected } \\
\text { prospectively }\end{array}$ & $\begin{array}{l}\text { Sample } \\
\text { representative }\end{array}$ & $\begin{array}{l}\text { Important } \\
\text { covariates } \\
\text { measured }\end{array}$ & $\begin{array}{l}\text { Important covariates } \\
\text { incorporated in } \\
\text { analysis }\end{array}$ & $\begin{array}{l}\text { Method of dealing with } \\
\text { confounding } \\
\text { adequate* }^{*}\end{array}$ \\
\hline Aronson $2008^{7}$ & Yes & Unclear & Yes & Yes & Yes \\
\hline Bernard $2009^{31}$ & No & Yes & Yes & Yes & Yes \\
\hline Bochicchio $2008^{8}$ & Yes & Yes & No & No & No \\
\hline Charles $2007^{32}$ & No & Yes & No & No & No \\
\hline Edgren $2010^{36}$ & No & Yes & No & No & No \\
\hline Engoren $2009^{9}$ & No & Yes & No & No & No \\
\hline Engoren $2009^{10}$ & No & Yes & No & No & No \\
\hline Garty $2009^{11}$ & No & Yes & Yes & Yes & Yes \\
\hline Jani $2007^{12}$ & No & No (>60 years) & Yes & Yes & Yes \\
\hline Johnson $2006^{13}$ & No & Unclear & No & No & No \\
\hline Khorana $2008^{14}$ & No & Yes & No & No & No \\
\hline Koch $2006^{1516}$ & Yes & Yes & Yes & Yes & Yes \\
\hline Koch $2008^{37}$ & No & Yes & Yes & Yes & Yes \\
\hline Murphy $2007^{17}$ & No & Yes & Yes & Yes & Yes \\
\hline Nikolsky $2009^{18}$ & Yes & Yes & Yes & Yes & Yes \\
\hline O'Keeffe $2010^{33}$ & Yes & Yes & No & No & No \\
\hline Pederson $2009^{19}$ & No & Yes & No & No & No \\
\hline Rogers $2006^{20}$ & No & No (>65 years) & No & No & No \\
\hline Rogers $2009^{21}$ & No & No (> 65 years) & No & No & No \\
\hline Ruttinger $2007^{34}$ & No & Yes & No & No & No \\
\hline Salehiomran $2009^{22}$ & No & Yes & Yes & Yes & Yes \\
\hline Stone $2008^{23}$ & No & No $(<16$ years $))$ & No & No & No \\
\hline Surgenor $2009^{24}$ & Yes & Yes & No & No & No \\
\hline Taylor $2006^{25}$ & Yes & Yes & No & No & No \\
\hline $\begin{array}{l}\text { van de Watering } \\
2006^{38}\end{array}$ & No & Yes & No & No & No \\
\hline van Straten $2010^{26}$ & Yes & Yes & No & No & No \\
\hline Vincent $2008^{27}$ & Yes & Yes & No & No & No \\
\hline Weightman $2009^{35}$ & Yes & Yes & No & No & No \\
\hline Weinburg $2008^{28}$ & No & Yes & No & No & No \\
\hline Weinburg $2008^{39}$ & No & Yes & No & No & No \\
\hline Wu $2010^{29}$ & No & No (> 65 years) & Yes & Yes & Yes \\
\hline Zilberberg $2008^{30}$ & No & Yes & No & No & No \\
\hline
\end{tabular}

considerable heterogeneity in the meta-analysis, suggesting that it might not have been appropriate to combine the results of the individual studies and supports our decision not to conduct a meta-analysis.

In an overview of evidence from randomised controlled trials, Wilkinson et $a t^{41}$ identified 142 trials in RBCT. The majority compared the effects of leucoreduced RBCT or different transfusion triggers $(n=71)$. However, they did identify 12 trials comparing the effects of RBCT versus no transfusion, 7 looking at different volumes of RBCT and 11 different ages of red blood cells. The size of the trials was very small (median 30-40 patients) and the overview did not specifically examine the effect of RBCT on mortality. Currently, we are aware of at least 14 ongoing or recently completed randomised controlled trials examining the effects of the age of RBCT on clinical outcomes including the ARIPI (Age of Red blood cells In Premature Infants) ${ }^{42}$ ABLE, (Age of BLood Evaluation trial in the resuscitation of critically ill patients) ${ }^{43}$ RECESS (REd CEll Storage duration Study) ${ }^{(44}$ and INFORM (Effects of transfusing fresh versus standard-issue red cells on in-hospital mortality) trials, for which mortality or survival is a specified outcome measure.

\section{Limitations}

Our study has several limitations. First, we only included studies published in the last 5 years and which included more than 1000 patients. This was because we took a pragmatic approach as we hypothesised that more recent studies were more likely to use better statistical methods and also that studies with a larger sample size were more likely to show a truer effect of the intervention. ${ }^{45}$ Thus, we aimed to provide a 'snapshot' of current practice rather than provide a comprehensive review of all available evidence. It is possible, therefore, that the overall effect seen here might be different in older studies and/or in those carried out in smaller 
numbers of patients. Second, we decided not to combine the results of individual studies because of the variability in clinical settings and study methods, and instead presented the results of individual studies descriptively in the text and in tables and figures. More formal statistical analysis might have given a more precise indication of the overall effect of red cell transfusion on mortality, but would have ignored the significant amount of clinical and methodological heterogeneity between studies which we identified a priori and which was very apparent in the analysis done by Marik and Corwin. ${ }^{40}$ However, in the absence of a more formal statistical analysis, we have inevitably had to rely on a votecounting approach which also has great dangers, particularly the assumption that each included study has equal weight. Our main protection against this is the very pronounced nature of the pattern we have observed and the fact that we have limited our conclusions to the direction of effect.

Finally, we limited our inclusion criteria to published articles and excluded unpublished studies or those published only as conference abstracts; thus, our study could be subject to publication bias, as studies which did not show a significant effect of red cell transfusion on mortality might have been less likely to be published in full. ${ }^{46}$ Outcome reporting bias may also be a problem, although difficult to combat, in the case where a risk has been measured at different time points but only those time points which are 'positive' are reported. However, in the case of both publication and outcome reporting bias, the extreme nature of the pattern makes it relatively implausible that there are sufficient unpublished studies or time points to reverse it.

\section{Implications for clinical practice}

In recent years, many developed countries including the UK, the USA and Australia have developed national initiatives for better blood transfusion practice, sometimes called 'patient blood management'. 5 These include the development of guidelines on blood usage promoting restrictive transfusion strategies and initiatives for using alternatives to transfusion (eg, cell salvage techniques; improvements in the education and training of clinical staff prescribing blood; the provision of mechanisms for reviewing blood use with feedback of data to clinicians). National data on blood usage in the USA suggest an estimated decline of $3 \%$ over each of the last two 2 years $(2009-2010),{ }^{4}$ and similar data are available in the UK where the demand for red cell units, which steadily increased during the 1990s, has decreased by about $20 \%$ in the last 10 years. However, there remains considerable variation between hospitals in blood reduction, and national audits of blood components in the UK and elsewhere suggest that overall blood usage could be further reduced without compromising patient safety. ${ }^{3}$

It is difficult to assess how observational studies may have influenced these changes in transfusion practice in comparison to evidence from randomised controlled trials, national guidelines and process driven initiatives. The most likely answer is that they have all played a role in changing practice. Randomised controlled trials have found that 'restrictive' transfusion strategies are associated with similar or improved clinical outcomes compared with 'liberal' transfusion strategies. ${ }^{47}$ Many national guidelines have adopted restrictive transfusion strategies, ${ }^{47}$ while needing to make assumptions about the generalisability of the findings of randomised controlled trials in specific clinical groups of patients. There have been many smaller observational studies of process initiatives to reduce transfusion that also indicate reductions in the use of blood without any significant impact on clinical outcomes. ${ }^{48-50}$

\section{CONCLUSION}

The findings from this systematic review of recent large-scale observational studies show considerable variability in the patient populations and study methods when comparing the effects of RBCT on mortality. Overall, the observational studies do show a consistent adverse effect of RBCT on mortality. Although it seems unlikely that this can be entirely explained by selective sampling or a predominance of poorer quality observational studies, it remains possible that even the best conducted adjustments cannot completely eliminate the impact of confounding.

Acknowledgements We are grateful to Susan Brunskill for her helpful comments on this manuscript.

Contributors $\mathrm{SH}$ and 00 were involved in the design, implementation and analysis of the study, as well as in the writing of the final manuscript. $\mathrm{CH}$, MFM and L-MY were involved in the design and analysis of the study and in the writing of the final manuscript.

Funding This study was funded by NHS Blood and Transplant, Research and Development, UK.

Competing interests None.

Patient consent Obtained.

Provenance and peer review Not commissioned; externally peer reviewed.

Data sharing statement No additional data are available.

\section{REFERENCES}

1. Blajchman MA. Landmark studies that have changed the practice of transfusion medicine. Transfusion 2005;45:1523-30.

2. Deeks JJ, Dinnes J, D'Amico R, et al. Evaluating non-randomised intervention studies. Health Technol Assess 2003;7:1-173.

3. Murphy MF, Stanworth SJ, Yazer M. Transfusion practice and safety: current status and possibilities for improvement. Vox Sang 2011;100:46-59.

4. Goodnough LT, Shander A. Patient blood management. Anesthesiology 2012;116:1367-76.

5. NHS blood transfusion and transplant/Royal College of Physicians national comparative audit of blood transfusion programme. http:// hospital blood co uk/safe_use/clinical_audit/national_comparative/ indexasp (accessed 5 Mar 2013).

6. Bennett-Guerrero $\mathrm{E}, \mathrm{Zhao} \mathrm{Y}, \mathrm{O}$ 'Brien $\mathrm{SM}$, et al. Variation in use of blood transfusion in coronary artery bypass graft surgery. JAMA 2010;304:1568-75.

7. Aronson D, Dann EJ, Bonstein L, et al. Impact of red blood cell transfusion on clinical outcomes in patients with acute myocardial infarction. Am J Cardiol 2008;102:115-19. 
8. Bochicchio GV, Napolitano L, Joshi M, et al. Outcome analysis of blood product transfusion in trauma patients: a prospective, risk-adjusted study. World J Surg 2008;32:2185-9.

9. Engoren $\mathrm{M}$, Habib $\mathrm{RH}$, Hadaway $\mathrm{J}$, et al. The effect on long-term survival of erythrocyte transfusion given for cardiac valve operations. Ann Thorac Surg 2009;88:95-100.

10. Engoren $\mathrm{M}$, Arslanian-Engoren $\mathrm{C}$. Long-term survival in the intensive care unit after erythrocyte blood transfusion. Am J Crit Care 2009;18:124-31.

11. Garty M, Cohen E, Zuchenko A, et al. Blood transfusion for acute decompensated heart failure-friend or foe? Am Heart $J$ 2009;158:653-8.

12. Jani SM, Smith DE, Share D, et al. Blood transfusion and in-hospital outcomes in anemic patients with myocardial infarction undergoing percutaneous coronary intervention. Clin Cardiol 2007;30(10 Suppl 2):II49-56.

13. Johnston $\mathrm{P}$, Wynn-Jones $\mathrm{H}$, Chakravarty $\mathrm{D}$, et al. Is perioperative blood transfusion a risk factor for mortality or infection after hip fracture? J Orthop Trauma 2006;20:675-9.

14. Khorana AA, Francis CW, Blumberg N, et al. Blood transfusions, thrombosis, and mortality in hospitalized patients with cancer. Arch Intern Med 2008;168:2377-81.

15. Koch CG, Li L, Duncan Al, et al. Morbidity and mortality risk associated with red blood cell and blood-component transfusion in isolated coronary artery bypass grafting. Crit Care Med 2006;34:1608-16.

16. Koch CG, Li L, Duncan Al, et al. Transfusion in coronary artery bypass grafting is associated with reduced long-term survival. Ann Thorac Surg 2006;81:1650-7.

17. Murphy GJ, Reeves BC, Rogers CA, et al. Increased mortality, postoperative morbidity, and cost after red blood cell transfusion in patients having cardiac surgery. Circulation 2007;116:2544-52.

18. Nikolsky E, Mehran R, Sadeghi HM, et al. Prognostic impact of blood transfusion after primary angioplasty for acute myocardial infarction: analysis from the CADILLAC (Controlled Abciximab and Device Investigation to Lower Late Angioplasty Complications) Trial. JACC Cardiovasc Interv 2009;2:624-32.

19. Pedersen AB, Mehnert F, Overgaard S, et al. Allogeneic blood transfusion and prognosis following total hip replacement: a population-based follow up study. BMC Musculoskelet Disord 2009;10:167.

20. Rogers MA, Blumberg N, Saint SK, et al. Allogeneic blood transfusions explain increased mortality in women after coronary artery bypass graft surgery. Am Heart J 2006;152:1028-34.

21. Rogers MA, Blumberg N, Saint $\mathrm{S}$, et al. Hospital variation in transfusion and infection after cardiac surgery: a cohort study. BMC Med 2009;7:37.

22. Salehiomran A, Ahmadi $H$, Karimi $A$, et al. Transfusion associated in-hospital mortality and morbidity in isolated coronary artery bypass graft surgery. Cent Eur J Med 2009;4:286-92.

23. Stone TJ, Riesenman PJ, Charles AG. Red blood cell transfusion within the first 24 hours of admission is associated with increased mortality in the pediatric trauma population: a retrospective cohort study. J Trauma Manag Outcomes 2008;2:9.

24. Surgenor SD, Kramer RS, Olmstead EM, et al. The association of perioperative red blood cell transfusions and decreased long-term survival after cardiac surgery. Anesth Analg 2009;108:1741-6.

25. Taylor RW, O'Brien J, Trottier SJ, et al. Red blood cell transfusions and nosocomial infections in critically ill patients. Crit Care Med 2006;34:2302-8.

26. van Straten AH, Bekker MW, Soliman Hamad MA, et al. Transfusion of red blood cells: the impact on short-term and long-term survival after coronary artery bypass grafting, a ten-year follow-up. Interact Cardiovasc Thorac Surg 2010;10:37-42.

27. Vincent JL, Sakr Y, Sprung C, et al. Are blood transfusions associated with greater mortality rates? Results of the Sepsis Occurrence in Acutely III Patients study. Anesthesiology 2008:108:31-9.

28. Weinberg JA, McGwin G Jr, Marques MB III, et al. Transfusions in the less severely injured: does age of transfused blood affect outcomes? J Trauma 2008;65:794-8.
29. Wu WC, Smith TS, Henderson WG, et al. Operative blood loss, blood transfusion, and 30-day mortality in older patients after major noncardiac surgery. Ann Surg 2010;252:11-17.

30. Zilberberg MD, Stern LS, Wiederkehr DP, et al. Anemia, transfusions and hospital outcomes among critically ill patients on prolonged acute mechanical ventilation: a retrospective cohort study. Crit Care 2008;12:R60.

31. Bernard AC, Davenport DL, Chang PK, et al. Intraoperative transfusion of $1 \mathrm{U}$ to $2 \mathrm{U}$ packed red blood cells is associated with increased 30-day mortality, surgical-site infection, pneumonia, and sepsis in general surgery patients. J Am Coll Surg 2009;208:931-7.

32. Charles A, Shaikh AA, Walters M, et al. Blood transfusion is an independent predictor of mortality after blunt trauma. Am Surg 2007;73:1-5.

33. O'Keeffe SD, Davenport DL, Minion DJ, et al. Blood transfusion is associated with increased morbidity and mortality after lower extremity revascularization. J Vasc Surg 2010;51:616-21.

34. Ruttinger $\mathrm{D}$, Wolf $\mathrm{H}$, Kuchenhoff $\mathrm{H}$, et al. Red cell transfusion: an essential factor for patient prognosis in surgical critical illness? Shock 2007;28:165-71.

35. Weightman WM, Gibbs NM, Sheminant MR, et al. Moderate exposure to allogeneic blood products is not associated with reduced long-term survival after surgery for coronary artery disease. Anesthesiology 2009;111:327-33.

36. Edgren G, Kamper-Jorgensen M, Eloranta S, et al. Duration of red blood cell storage and survival of transfused patients (CME). Transfusion 2010;50:1185-95.

37. Koch CG, Li L, Sessler DI, et al. Duration of red-cell storage and complications after cardiac surgery. $N$ Engl $J$ Med 2008;358:1229-39.

38. van de Watering L, Lorinser $\mathrm{J}$, Versteegh $\mathrm{M}$, et al. Effects of storage time of red blood cell transfusions on the prognosis of coronary artery bypass graft patients. Transfusion 2006;46:1712-18.

39. Weinberg JA, McGwin G Jr, Griffin RL, et al. Age of transfused blood: an independent predictor of mortality despite universal leukoreduction. J Trauma 2008;65:279-82.

40. Marik PE, Corwin HL. Efficacy of red blood cell transfusion in the critically ill: a systematic review of the literature. Crit Care Med 2008;36:2667-74.

41. Wilkinson KL, Brunskill SJ, Doree C, et al. The clinical effects of red blood cell transfusions: an overview of the randomized controlled trials evidence base. Transfus Med Rev 2011;25:145-55.

42. Fergusson DA, Hebert $\mathrm{P}$, Hogan DL, et al. Effect of fresh red blood cell transfusions on clinical outcomes in premature, very low-birth-weight infants: the ARIPI randomized trial. JAMA 2012;308:1443-51.

43. Lacroix J, Hebert P, Fergusson D, et al. The Age of Blood Evaluation (ABLE) randomized controlled trial: study design. Transfus Med Rev 2011;25:197-205.

44. Steiner ME, Assmann SF, Levy JH, et al. Addressing the question of the effect of RBC storage on clinical outcomes: the Red Cell Storage Duration Study (RECESS) (Section 7). Transfus Apher Sci 2010;43:107-16.

45. Dechartres A, Boutron I, Trinquart L, et al. Single-center trials show larger treatment effects than multicenter trials: evidence from a meta-epidemiologic study. Ann Intern Med 2011;155:39-51.

46. Scherer RW, Langenberg P, von EE. Full publication of results initially presented in abstracts. Cochrane Database Syst Rev 2007; (2):MR000005.

47. Goodnough LT, Levy JH, Murphy MF. Current concepts in transfusion. Lancet 2013;[in press].

48. Kotze A, Carter LA, Scally AJ. Effect of a patient blood management programme on preoperative anaemia, transfusion rate, and outcome after primary hip or knee arthroplasty: a quality improvement cycle. Br J Anaesth 2012;108:943-52.

49. Freedman J, Luke K, Escobar M, et al. Experience of a network of transfusion coordinators for blood conservation (Ontario Transfusion Coordinators [ONTraC]). Transfusion 2008;48:237-50.

50. Helm RE, Rosengart TK, Gomez M, et al. Comprehensive multimodality blood conservation: 100 consecutive CABG operations without transfusion. Ann Thorac Surg 1998;65:125-36. 